\title{
The Researcher/Practitioner Strategic Partnership: Linking Theory and Prac- tice for Change in Engineering and Computer Science Education
}

\author{
Dr. Ella Lee Ingram, Rose-Hulman Institute of Technology
}

Ella L. Ingram is an Associate Professor of Biology and Director of the Center for the Practice and Scholarship of Education at Rose-Hulman Institute of Technology. Her educational research interests include promoting successful change practice of STEM faculty, effective evolution and ecology instruction, and facilitating undergraduate research experiences. Her teaching portfolio includes courses on: nutrition, introductory biology, ecology and environmental studies, evolution, evolutionary medicine, and research practices in science.

\section{Dr. Elizabeth Litzler, University of Washington}

Elizabeth Litzler, Ph.D., is the director of the University of Washington Center for Evaluation \& Research for STEM Equity (UW CERSE) and an affiliate assistant professor of sociology. She has been at UW working on STEM Equity issues for more than 12 years. Dr. Litzler is a member of ASEE and a former board member of the Women in Engineering ProActive Network (WEPAN). She is currently the principal investigator on a dozen different research and evaluation projects focused on improving equity, diversity, and inclusion in higher education. Her research interests include the educational climate for students in science and engineering, assets-based approaches to STEM equity, and gender and race stratification in education and the workforce.

\section{Dr. Cara Margherio, University of Washington}

Cara Margherio is a Senior Research Associate at the UW Center for Evaluation \& Research for STEM Equity (CERSE). Cara serves as project manager for program evaluation on several NSF- and NIH-funded projects. Her research interests include community cultural wealth, counterspaces, peer mentoring, and institutional change.

\section{Kerice Doten-Snitker, University of Washington}

Ms. Doten-Snitker is a Graduate Research Assistant at the University of Washington's Center for Evaluation and Research for STEM Equity, where she is part of a team conducting evaluation research for university-level educational and professional training, with a focus on increasing equity and participation of underrepresented and minority students and professionals. She has contributed to evaluation research for a range of programs funded by the NSF, NIH, and USAID. Additionally, she is a Doctoral Candidate in Sociology at the University of Washington, where her scholarship focuses on political processes of inclusion and exclusion.

\section{Dr. Julia M. Williams, Rose-Hulman Institute of Technology}

Dr. Julia M. Williams is Interim Dean of Cross-Cutting Programs and Emerging Opportunities and Professor of English at Rose-Hulman Institute of Technology. Her research areas include technical communication, assessment, accreditation, and the development of change management strategies for faculty and staff. Her articles have appeared in the Journal of Engineering Education, International Journal of Engineering Education, IEEE Transactions on Professional Communication, and Technical Communication Quarterly, among others. 


\section{The Researcher/Practitioner Strategic Partnership: Linking Theory and Practice for Change in Engineering and Computer Science Education}

Our NSF-funded collaborative project-REvolutionizing engineering and computer science departments (RED) Participatory Action Research (PAR) - represents a strategic partnership between researchers and practitioners in the domain of academic change. The principle investigators from the Making Academic Change Happen (MACH) team from Rose-Hulman Institute of Technology provide familiarity with the literature of practical organizational change and package this research into action-oriented workshops and ongoing support for teams funded through the RED program (IUSE/PFE: RED). The PIs from the University of Washington Center for Evaluation \& Research for STEM Equity (CERSE) provide expertise in social science research to investigate how the RED teams' change projects unfold and how the teams develop as members of national leadership cohorts for change in engineering and computer science education. This partnership represents a model that can be replicated by other scholars. According to Worrall (2007), good partnerships are "founded on trust, respect, mutual benefit, good communities, and governance structures that allow democratic decision-making, process improvement, and resource sharing." These elements exist in this partnership and create mutual benefits. For example, the researchers see an "insider's" perspective on the practitioners' approach - their goals, motivations for certain activities, and background information and research. Similarly, insights from the researchers provide both immediate and long-term benefits to programming and increased professional impact. The researchers are trained observers, each of whom brings a unique disciplinary perspective to their observations. In sharing our experiences with a researcher/practitioner partnership, we hope to encourage researchers to seek out partnerships with practitioners to bridge the gap between theory and practice in engineering and computer science education.

\section{Introduction}

Connecting research and practice is a challenge experienced by both researchers and practitioners in many disciplinary areas. In education, research results should intersect with policy and practice in ways similar to other disciplines, e.g., medicine $[1,2]$. Unfortunately, academic education research often ends up being inaccessible or not particularly useful to the practitioners who could benefit $[2,3]$. Higher education as an enterprise continually struggles with the challenges of connecting research like that done by members of ASEE with the everyday work experiences. A familiar set of questions arise from this situation. Researchers say, "Why don't educators use the strategies we know to increase student learning? Why don't educators seem to be interested in what we have to contribute to their classrooms? Practitioners say, "Why don't researchers provide information in a usable way? How do I translate their research to my institutional setting?" As professionals, we recognize that our work is negatively impacted by the lack of connection and communication between these two "worlds." Closing the gaps in the research to practice and the practice to research cycles is critical to move the field forward and serve stakeholders in higher education. Researcher-practitioner partnerships amplify 
impact, especially in participatory action research, and we recommend that researchers and practitioners both consider developing and maintaining partnerships.

\section{A Model Researcher-Practitioner Partnership}

Our partnership serves as a model of a successful researcher-practitioner partnership, and in the spirit of contribution to the field of engineering education, we explore the benefits and challenges of this partnership. This partnership has a defined purpose: to support and study the change efforts of grantees through NSF's REvolutionizing Engineering and Computer Science Departments (RED) program. These grantees are engaged in large-scale change in their departments or colleges, and as such are accomplishing challenging, complex work. The two-part purpose of our partnership, defined by support and study, highlights the need for a new kind of team: a team that possesses the skills to enact support and a team that possesses the skills to enact study. The partnership, known as REDPAR for RED Participatory Action Research, unites the team from Rose-Hulman Institute of Technology and the team from the University of Washington.

\section{The REDPAR Origin Story}

Effective partnerships emerge from personal relationships, rather than institutional efforts. We represent two independent groups, the researchers from the Center for Evaluation \& Research for STEM Equity from the University of Washington and the Making Academic Change Happen practitioners from Rose-Hulman Institute of Technology. The origin of our partnership occurred in the mid-2000's when one individual from MACH and one individual from CERSE met through a different national project, and subsequently maintained a loose professional connection. When NSF encouraged MACH to submit a proposal focused on supporting change for the RED program, MACH contacted CERSE and a joint proposal resulted. These first stages of developing the partnership brought to light the expertise contributed by both groups: MACH as experts in change strategies, and CERSE as experts in qualitative research. Our initial experiences suggested that we would work semi-collaboratively, with major responsibility falling along expertise lines. This prediction proved short-sighted; as the work progressed, our roles, contributions, and expertise have developed dramatically. Although we maintain specified areas of responsibility, the distance between research and practice has narrowed both incrementally and in step functions.

\section{Partnership Maintenance Activities}

We intentionally invest in team building. This effort is especially important as we are geographically separated and can't "grab lunch." Our team building efforts take many forms. We hold biweekly web-conference check-ins, keep a running action item list, use a shared Google Drive for most project work, schedule strategic retreat times, and use a listserv for email. These planned elements keep the project on track and keep us professionally connected. We also share personal triumphs and challenges, like major career accomplishments, ailing relatives, travels and adventures, progress on hobbies, and the latest pet antics. These aspects humanize the relationships among individuals in our partnership. By addressing both the professional and the personal, we enact Worrall's finding that good partnerships are "founded on trust, respect, mutual benefit, good communities, and governance structures that allow democratic decision-making, 
process improvement, and resource sharing" [4]. Further, by engaging in team building, we each peek into the lives of a compatriot in the research or practice realms.

\section{Unique Contributions to the REDPAR Partnership}

The researchers of CERSE are trained observers, and each brings a unique disciplinary perspective to their observations. The role of the researchers is to understand the process of change and experiences of the change teams, and to return this information to the change teams to promote project success. This approach is consistent with the philosophical goals of action research; essentially, the researchers ask "what can we [researchers] learn and share that can be useful to others [practitioners and change agents]?" The researchers are not involved in evaluation of the projects, as that work is done by independent evaluators associated with each individual team. The researchers contribute sociological, psychological, and organizational theory perspectives, focusing on interpersonal interactions, human dynamics, communication strategies, and power dynamics. The researchers observe interactions within change teams, facilitate focus groups, and summarize documentary evidence, among other activities. They share resulting data and analyses with the practitioners at a high level through verbal summaries, written reports, and key quotes pulled from the group. The primary benefit of the analyses and perspectives generated by researchers for practitioners is that practitioners gain new frameworks through which to view their work.

The practitioners of $\mathrm{MACH}$ have wide ranging experience with change efforts and operationalize change research by creating actionable strategies and meaningful learning experiences for change teams. The role of the practitioners with respect to the RED program is to support the change efforts of the change teams, and to share the information relating to team experiences with CERSE, ultimately to be shared with the RED consortium. This approach is consistent with the guiding philosophy of MACH: learn by collaborative doing. The practitioners are not involved in determining the specific change theories or next steps that the change teams pursue. The practitioners contribute real examples of change in higher education, pedagogical and facilitation expertise, and strategies culled from experience, research, and observation of other change teams. The practitioners host consortium conference calls, create content for workshops, and promote and support cross-team collaboration, among other activities. They share workshop plans, early warning signs of impending challenges change teams might experience, and best practices in change management with the researchers of CERSE. The primary benefit of the practitioners' work to the researchers is that the researchers gain access and information they would otherwise not have. This information, in turn, impacts both the direction of the research effort and the conclusions CERSE may draw from it.

\section{Outcomes of the REDPAR Partnership}

The partnership produces work that positively affects the professional work of the partners and their respective communities. Both partners have grown in expertise from the partnership. The practitioners learned significant lessons about qualitative research, from inception to data collection and analyses (e.g., coding transcripts), to disciplinary conventions of communication. Further, as a team, we engage in discussion about the fundamental assumptions of qualitative research and the stance of participatory action research as a research methodology. These discussions advanced the research literacy of the practitioners. Similarly, the researchers learned 
significant lessons about about pedagogy and facilitation, through both observation and discussion. These lessons have influenced the approach the researchers have taken in accomplishing data collection (e.g., focus group facilitation), and have increased their ability to make recommendations for content and delivery mechanisms likely to be valuable to the change teams. Working closely together creates a positive impact in expertise for both partners.

From a professional production perspective, the partnership has been successful. Many of the products we have produced have been created with an intentional focus on making the research results practical to the community. Without the expertise of both teams, the research products would have remained inaccessible or impractical for practitioners. We have engaged in a wide variety of outreach and dissemination efforts, both with the partners as coauthors and with individual members representing the partnership and assuming authorship credit. We have produced both individual and joint publications and presentations and shared our work across platforms [e.g., 13, 14, 15, 16]. For example, we identified that effective communication was a challenge for change teams; they were communicating with multiple stakeholders, all requiring different parts of the story, and confusion resulted among stakeholders. One researcher, one practitioner, and two change agents collaborated to produce a communication workshop centered on coordination across communication needs (e.g., what marketing professionals might call "branding") [13]. We used examples from the change agents' project to highlight key points. In another example, one researcher and one practitioner collaborated to produce a session at a conference aimed at disseminating practical strategies for developing partnerships. The researcher described key highlights from the research about developing strategic partnerships, and the practitioner translated those highlights into actionable strategies for session attendees. This give-and-take presentation style highlighted our focus on connecting research and practice. The partnership's orientation toward outreach and dissemination had a positive impact on one member's professional advancement. In total, we produced more than 20 professional products in less than three years.

The impact of the work of the partnership has been amplified because of the collaboration. From the research side, one of the recent findings is that many teams utilized informational communication, in which change leaders provide details about plans and goals, essentially offering a proposition for faculty to join or resist. In contrast, formational communication empowers faculty or other stakeholders to contribute to the change process, offering alternative or additional ideas for goals or how to implement the change, and this can have strong effects on the extent to which teams can move forward with their change projects $[14,17]$. This research finding is completely obvious in retrospect, but neither practitioner would have captured the strength and importance of this outcome without the qualitative data to back it up. From the practice side, a similar major lesson developed regarding the disconnection between self-assessed competencies of change agents (e.g., skills to advocate for a project) and their demonstrated competencies in practice (e.g., how they describe their project to colleagues). This practical outcome has directed the focus of the researchers toward collecting additional data on how change teams talk about their projects, developing hypotheses around how the ability to succinctly describe a project may impact change teams' progress.

\section{Discussion}


Researcher-practitioner partnerships connect all the links in the research to practice to research cycle. These connections are recognized in other disciplinary areas such as academic and clinical medicine combined into health services research [5], economic development [6], and education research [7]. In engineering education, many scholars have called for "closing the loop" of the research-to-practice cycle $[8,9,10]$.

Strategic partnerships are challenging to establish and maintain. Researchers studying academic partnerships have found that getting partners to align their goals is a critical early step and is often not explicitly addressed or appropriately resolved prior to significant forward action [11]. In our case, the alignment of goals among the partners is clear: research and support to serve the larger engineering education community. Partners may find that professional needs, experiences, and goals diverge over time. To make sure that the partnership continues to serve needs of the partners, we constantly communicate about our professional needs and the direction and limits of the project. Both organizations and individuals must be served by the partnership for it to be successful. Eddy and Amey highlighted the critical nature of regularly reviewing the operations and processes of an academic partnership to ensure continued success [12]. They also noted that partnerships can end amicably, both before completion of the partnership goals or once accomplished. Given that researchers and practitioners often have varying goals, keeping an open line of communication in a partnership will help ensure the appropriate maintenance and close of a relationship.

The partnership we established can serve as a model for successful researcher-practitioner partnerships. The beneficial outcomes of such a partnership make it an obvious choice for people who want to broaden the impact of their work. Given the calls for a stronger connection between research and practice, higher education would benefit if more researchers worked with practitioners and more practitioners worked with researchers. Although such partnerships can be challenging to develop and maintain, the potential for transformative outcomes is larger than independent work in either area can claim.

\section{References}

1 S. Ikenberry, "Scholarship and practice in higher education: What lies at the intersection?" Higher Education in Review, vol. 8, pp. 1-12, 2011.

2 G. Keller, "Trees without fruit: The problem with research about higher education," Change, vol. 17 , no. 1 , pp. 7-10, 1985.

3 M. W. Sallee \& J. T. Flood, "Using qualitative research to bridge research, policy, and practice," Theory Into Practice, vol. 51, no. 2, pp. 137-144, 2012.

4 L. Worrall, "Asking the community: A case study of community partner perspectives," Michigan Journal of Community Service Learning, vol. Fall, pp. 5-17, 2007.

5 K. N. Lohr and D. M. Steinwachs, "Health services research: An evolving definition of the field," Health Services Research, vol. 37, no. 1, pp. 15-17, 2002.

6 A. Chib and R. Harris, Linking Research to Practice: Strengthening ICT for Development Research Capacity in Asia, Singapore: ISEAS Publishing, 2012. [E-book] Available for download: https:/www.idrc.ca/en/book/linking-research-practice-strengthening-ictdevelopment-research-capacity-asia 
7 Harvard Graduate School of Education, "Usable Knowledge: Connecting Research to Practice," Available at https://www.gse.harvard.edu/uk.

8 J. Turns, M. Cardella, C. J. Atman, J. Martin, and J. Newman, "Tackling the research-to-teaching challenge in engineering design education: Making the invisible visible," International Journal of Engineering Education, vol. 22, no. 3, pp. 598-608, 2006.

9 B. K. Jesiek, M. Borrego, and K. Beddoes, "Advancing global capacity for engineering education research (AGCEER): Relating research to practice, policy, and industry," Journal of Engineering Education, vol. 99, no. 2, pp. 107-119, 2010.

10 C. C. Samuelson, E. Litzler, and J. A. Lorah, "Collaboration between researchers and practitioners for mutual benefit," American Educational Research Association Annual Meeting, Philadelphia, PA, 2014.

11 P. L. Eddy, "Special Issue: Partnerships and Collaborations in Higher Education," Association for the Study of Higher Education (ASHE) Higher Education Report, vol. 36, no. 2, pp. 1-115, 2010.

12 P. L. Eddy and M. J. Amey, Creating Strategic Partnerships: A Guide for Educational Institutions and Their Partners, Sterling, VA: Stylus Publishing, 2014.

13 E. L. Ingram, B. Sukumaran, T. Forin, and E. Litzler, "Increase your project's success through coordinated communication: Research and practice," Workshop presented at Frontiers in Education, Indianapolis, IN, 2017.

14 E. L. Ingram, E. Litzler, C. Margherio, and J.M. Williams, "Learning to make change by revolutionizing departments: initial team experiences," American Society for Engineering Education, Columbus, OH, 2017

15 E. L. Ingram, "Changing your department: Examples from revolutionizing engineering and computer science departments," Frontiers in Education, Erie, PA, 2016.

16 J. M. Williams and E. L. Ingram, "Diversity and inclusion in civil and environmental engineering," Workshop presented at Rowan University Civil and Environmental Engineering Department, Glassboro, NJ, 2017.

17 C. Margherio, E. Litzler, and K. M. Doten-Snitker, "Developing a shared vision for change: New results from the REvolutionizing engineering and computer science Departments Participatory Action Research,” American Society for Engineering Education, Columbus, OH, 2017. 